\title{
LA RECIPROCIDAD EN LA RESOLUCIÓN DE CONFLICTOS EN EL VALLESPIR (ROSSELLÓN, FRANCIA): LOS DELITOS POR OFENSAS SEXUALES ${ }^{1}$
}

\author{
Silvia Gómez Mestres \\ Universitat de Barcelona
}

ABSTRACT: This essay deals with norms and standards of behaviour which influenced at the early ninetheenth century the criminalization and then the resolution of verbal injuries and acts of violence at the Vallespir's French villages. The analysis of the judicial procedure including the system of its resolution and the final sentence, leads to taking legal norms and social perceptions into account as a sources of the law. The delictual obligation - who entails both a material and a moral amends - takes part on the relationship which links the guilty (debtor) to the victim (creditor). This study aims to study the alternative modes of resolution —such as transactions-and the kind of reality affected by juridical arrangements. The following questions are considered: A) In what extent the cost of a transaction depends on other transactions (e.g. the importance of a process of abstraction as a equivalent measures that is built by material and mental arrangements)? B) In what extent this cost depends on the singular conditions of the transaction (i.e. the circumstances under which the offence takes place and the transaction takes part, the quality of the protagonists and the global context)? C) It is possible to isolate, within the indemnity, the physical or moral amends -i.e. the pain-from the legal damages amends? D) Can we isole the hurt from their cost?

En el presente trabajo me propongo analizar los llamados acuerdos, transacciones, arreglos de conflictos o conciliaciones a precio de dinero en los casos de delitos sexuales que se realizan al lado y tomando parte de las resoluciones judiciales del s. XIX en la región del Vallespir (Rossellón, Francia). Con este

1 Este trabajo forma parte de una tesis doctoral sobre la justicia en el siglo XIX en la región del Vallespir (Rosellón, Francia). Este investigación se está siendo sostenida por una beca de "Recerca y Docencia" de la Universidad de Barcelona. 
propósito intentaré argumentar como las transacciones consisten en un acuerdo que, en la medida que se establece por negociación, es contingente a las dos partes en disputa y que, en base a una relación de intercambio conmutativo, se fundamenta en una relación de reciprocidad que tiene lugar entre ambas partes sujeta a su satisfacción y conveniencia personal. En este sentido la relación que se entabla entre los pleiteantes no se establece en vistas a un «bien general» o principio de equidad valido para todo el mundo. Por el contrario, la negociación comporta argumentos en términos de normas y estandars compartidos entre los actores y que se someten a una operación de justa valoración de equivalencias que hace posible una relación de intercambio. Así pues, la negociación a través de la valoración está siempre restringida a cierta adherencia a valores y estandards comunes y aceptados, y por conscuentemente estas resoluciones son más o menos oportunistas (Gulliver, P.H., 1972).

Con el ánimo de combatir la arbitrariedad en la evaluación, juicio y aplicación de las penas correspondientes a la transgresión expuesta a juicio, las reformas judiciales del s. XIX trataron de evitar la preponderancia que en el s. XVIII habían obtenido ciertos recursos y figuras jurídicas como la transacción. Para ello, la intervención de la transacción en los juicios fue sometida a las disposiciones del derecho formal con el fin de regular y controlar los arreglos privados de los conflictos entre particulares. A pesar de estas reformas la gente del Vallespir adaptó el marco formal del sistema judicial a sus propias demandas. Así pues, en esta región el recurso a la resolución de conflictos que se establecen por negociación se incorpora al derecho penal por medio de sistemas de adjudicación, donde una tercera parte con autoridad y fuerza vinculante pronuncia una decisión (Gulliver, P.H., 1972). De esta forma, el uso de estas estrategias judiciales permitirá, a través de los medios que proporciona el derecho formal, mantener la visión local sobre la justicia proporcionando las bases para garantizar el éxito de una justicia local, y el control y la influencia de ciertos sectores de la sociedad sobre la misma. Con lo que se creará un derecho al margen del derecho legislado pero completamente legal, adaptado a las circunstancias de cada caso.

Reciprocidad y transacción penal: las relaciones de intercambio en la reparación de las ofensas

Tenemos que situar la transacción en tanto que modo de resolución de conflictos en el desarrollo histórico del derecho penal y el procedimiento legal. 
Ambos se encuentran vinculados a una cuestión política central, la relación entre el Estado y la sociedad. Ésta relación está descrita en derecho a través de la progresiva distinción así como de los diferentes niveles de interacción que existen entre el ámbito público y el ámbito privado. Dentro del ámbito público, el derecho es represivo y la introducción de las instituciones públicas en la vida social a través de castigos públicos es una de las características más relevantes de este tipo de justicia. En cambio, dentro del ámbito privado, donde no tiene lugar la justicia represiva, el derecho es conciliatorio (Carbasse, J.M., 2000). La distinción entre ambas esferas, se usa como criterio de clasificación de las figuras legales. En este sentido, la transacción situada en el ámbito privado -el derecho conciliatorio- es un acuerdo establecido entre ambas partes en disputa por medio de la negociación. Así que la negociación es una relación de intercambio bilateral que se establece entre los pleiteantes. El lazo que une ambas partes es la herida, es decir, un derecho que ha sido usurpado. De esta forma la herida tiene que repararse mediante el proceso de negociación estableciendo una relación de intercambio que se describe de la siguiente manera: a) usurpar un derecho, b) compensar el derecho usurpado - lo que significa reconocer la culpabilidad y responsabilidad por parte del ofensor-, c) aceptar la compensación - lo que significa que el ofendido responde afirmativamente a la reparación del derecho que le ha sido usurpado- (Ver Verdier, Raymond, 1999). Dicho de otra forma, la relación de intercambio quedaría como: a) quitar, b) devolver y c) aceptar. En este sentido la transacción describe una relación de intercambio entre las partes involucradas en el conflicto donde la herida se repara a través de un pago económico, un ofrecimiento de bienes, haciendo una promesa o reconociendo la ofensa. Cada una de las diferentes modalidades de indemnización dependerán del caso judicial y la negociación a la que se llegue.

El grado de influencia de la transacción en la justicia difiere en función del procedimiento legal, de los recursos y prerrogativas del derecho. A través del procedimiento legal podemos ver la relación entre el ámbito público y el ámbito privado. Esta relación depende de la libertad de intervención de las partes en disputa en la decisión judicial (Kehlmann, H., 1934). Y esta libertad de intervención depende a la vez del procedimiento legal. Existen dos tipos de procedimiento: El procedimiento acusatorio en el que las conclusiones judiciales a las que se llegan se obtienen mediante un proceso de enjuiciamiento y defensa. La principal obligación del fiscal y la defensa consiste en ajustar sus respectivos puntos de vista dentro de los limites de las reglas de la evidencia mientras que 
el juez actúa como arbitro imparcial con el fin de permitir que los hechos sobresalgan de su procedimiento. Por el contrario, el procedimiento inquisitivo es un sistema de la justicia criminal en el cual la verdad es revelada mediante una investigación sobre los hechos llevada a cabo por el juez. Es en este sistema es el juez quien toma la iniciativa e interroga a los testimonios más que la acusación y la defensa (Dictionary of Law; Oxford University Press, 1997). El procedimiento acusatorio favorece los acuerdos privados mucho más que el procedimiento inquisitorio. En este tipo de procedimiento, la resolución de disputas a través del sistema judicial es una opción a la que se opta en último recurso (Carbasse, J.M., 2000). Pero en la práctica, ambos sistemas de procedimiento se mezclan y actúan en función al tipo de ofensa, la gravedad y la clasificación que ésta obtiene y que es diferente en cada momento histórico.

En la medida que, a través de la historia del procedimiento legal, la libertad de intervención del ámbito privado del derecho se va reduciendo, la legitimidad de la transacción depende de la decisión judicial ejecutada por una autoridad legal. Por lo tanto, la transacción pierde su carácter original y se incorpora en el más estricto sistema legal. De esta forma, la transacción se equipara a la acción civil que sólo regula los intereses civiles de los procedimientos penales, (por ejemplo, demandas de compensación). El control sobre las transacciones penales tiene lugar, sobretodo, de dos formas (Kehlmann, $\mathrm{H}$., 1934): a) Reduciendo las ventajas originalmente ligadas a la transacción en tanto que perdón y paz concluida entre dos personas o, igualmente, entre dos grupos cuyo objetivo era eliminar las consecuencias y luchas que comportaba la disputa. Progresivamente, los sistemas coercitivos son introducidos y desplazan los efectos conciliatorios de la transacción persuadiendo a las partes en disputa a llevar los casos ante la justicia formal. b) No permitiendo el uso de la transacción para conciliar ciertos crímenes. Así pues, durante el Antiguo Régimen y a partir de la Ordenanza de 1670, las transacciones eran aceptadas en los crímenes que merecían penas infamantes, y las partes podían transaccionar para las demandas civiles en todos aquellos casos que no merecían la pena aflictiva. Sólo en estas ocasiones el ministerio público se abstenía de proseguir con la persecución del crimen. En cambio, si se trataba de un crimen que tenía que ser castigado por una pena aflictiva o la pena capital, la transacción realizada por los intereses civiles no podía detener el curso del procedimiento judicial.

Sin embargo, la evolución del derecho a través del tiempo se ha caracterizado por la coexistencia de diferentes órdenes sociales y jurídicos. Asimismo hasta bien entrado el siglo XVIII, tanto el aspecto público de los crímenes 
como la autoridad legal del poder real en la resolución de conflictos no pudieron evitar en su totalidad el uso de las transacciones. La flexibilidad del derecho de Antiguo Régimen junto con la existencia de prerrogativas y estrategias legales que permitían la introducción del punto de vista local sobre la evaluación, valoración y resolución de los hechos sometidos a juicio favorecían la transacción como recurso habitual de intervención en la conciliación de disputas. De este modo, a pesar de que el uso de transacciones en los casos de violación era frecuente durante el s. XVIII, la pena para estos tipos de delitos era la pena capital. Si bien la ordenanza de 1670 no aceptaba la transacción para los crímenes sujetos a la persecución de la acción pública, parece ser que en los casos por violación su uso era habitual. Según los comentarios del derecho recogidos en el Tratado de crímenes del Consejo Soberano del Rosellón, el castigo por el delito de violación fue uno de los más debatidos entre los jurisconsultos del s. XVIII. La pena capital era la punición mayormente aceptada por los hombres del derecho, pero no todas las opiniones coincidían y las discrepancias sobre la valoración de la gravedad del delito de violación, que variaba en función al tipo de violación y a las circunstancias en que se desarrollaba, hacía dudar sobre si aplicar o no el castigo más severo o bien una pena más indulgente como las llamadas penas infamantes. Por ejemplo, no se consideraba igualmente una violación sobre una mujer inmadura que una violación sobre una mujer madura, y si ésta estaba en la edad de casarse, era viuda, o casada también eran aspectos a tener en consideración. Otros aspectos eran la cualidad de las personas de la víctima y del culpable, las edades respectivas, y si el acto carnal había sido consumido o no. Todas estas circunstancias hacían dudar a los letrados sobre el tipo de pena que merecía la violación, lo que indicaría la aceptabilidad o no de la transacción como medio de resolución. De todas formas, el recurso a la transacción como conciliación durante el s. XVIII en Francia fue muy corriente, fuera esta o no aceptada para dar por terminado un proceso judicial. Según Vigarello (1999), a pesar de su legalidad o ilegalidad, parece ser que la transacción podría haber sido una forma de evitar el recurso a una justicia demasiado lejana o inquietante.

La idea que la justicia tiene que procurar por la protección individual y que sólo puede asegurarse a través de la administración de la justicia que proporciona el Estado no se consolidará hasta el s. XIX. Bajo este precepto, la transacción se incorporará al derecho formal con el fin de sujetarla y someterla al control de la justicia estatal y evitar, de esta forma, cualquier otro tipo de resolución que escape a la solución judicial. Con ello, se pretende evitar la arbitra- 
riedad juridica enfrentando la transacción con la repuesta que proporciona la resolución judicial con la aplicación de las leyes. Así pues, se aplicará la ley correspondiente de acuerdo a las características de la transgresión y, por lo tanto, no dejando espacio alguno a la negociación de la reparación del mal cuyo resultado, sujeto a un regateo y ajustamiento continuo de valoraciones expuestas a la libre interpretación de sus implicados, era considerado poco equitativo, demasiado aleatorio y, además, acusado de promocionar la inseguridad entre los individuos. El jurisconsulto del Rosellón Lafabrègue, señala la transacción como un recurso que promueve la absolución guardando a los delincuentes bajo el amparo de los efectos de la conciliación. Así, con el fin de reformar la justicia en virtud de la equidad, la protección del individuo y la justa resolución de los conflictos, la transacción sólo será aceptada y exclusivamente en tanto que indemnización para los fines civiles. Es decir, mientras el ministerio público se encargaba de la persecución de los crímenes y los delitos, las partes podían acordar los daños y prejuicios.

Así, durante el siglo XIX la transacción de acuerdo con el artículo 2044 del código civil francés (1804) es «un contrato a través del cual las partes terminan una contestación judicial o evitan una contestación que tiene que nacer" (...). Lo que significa que la transacción es un contrato consensual al mismo tiempo que commutativo y fortuito en la medida que el sacrificio realizado por cada parte es considerado como equivalente a lo que éstos obtienen. Ésta equivalencia es la suerte de ganar o perder un juicio. Otra de las condiciones indispensables para que la transacción sea válida es que el juicio tiene que ser incierto en las mentes de quienes realizan la transacción. En este sentido, el prototipo de pleito en el cual interviene la transacción es el de un estatus incierto (Lacanterie, G.B., 1899). Por otra parte, el artículo 2046 dispone que «es posible hacer uso de la transacción para los intereses civiles que resultan de una ofensa.-La transacción no evita la persecución del ministerio publico". De este texto podemos deducir que no es posible realizar la transacción para la acción pública que resulta de una ofensa. El ofensor no puede llegar a un acuerdo en estos casos ni con el ministerio público, que está instituido para ejercer la acción pública en nombre de la sociedad tal y como dicta el articulo 249 del código civil (1804) y cuyo fondo es el de mantener a la acción pública independiente de los acuerdos a los que lleguen las partes. De otra forma, el pago de una suma a cambio de la promesa de retirar la denuncia es una transacción ilegal puesto que no se puede considerar como una transacción por intereses civiles (Idem). 
Partiendo de este contexto, durante la primera mitad del s. XIX, el uso de la transacción en los conflictos como medio de conciliación entre los particulares no fue poco común en Francia (ver Ploux, F., 1992, y Soulet, J.-V., 1979). Las transacciones analizadas se presentan bajo dos modalidades distintas: 1) fuera del sistema legal. Es decir, cuando la disputa no se resuelve en los tribunales y se acuerda un arreglo sin juicio. Este tipo de transacción suele conllevar el desistimiento del pleito. 2) dentro del sistema legal. En este caso el proceso de negociación está completamente incorporado al curso de la justicia y se equipara a las demandas civiles particulares sin tener en cuenta las disposiciones legales. Ambas negociaciones pueden ser mediadas por una tercera parte que no tiene capacidad para emitir ninguna decisión vinculante y que sólo actúa como garante del acuerdo. En el Rosellón, estos mediadores suelen ser gente influente entre la comunidad o las mismas autoridades municipales.

Según el tipo de delito, la pena que le corresponde y la jurisdicción encargada de juzgarlo la transacción se realizará dentro del derecho formal o fuera del derecho formal, y ocupará un lugar u otro dentro de los limites de la aceptabilidad legal. Así, por ejemplo, el uso de las transacciones fuera de los tribunales era completamente aceptado, tanto en el antiguo derecho penal francés como en el primer código penal francés, para los casos concernientes a las ofensas verbales (Lacanterie, G.B., 1899). La gravedad del insulto no merecía una disposición específica en las leyes del código penal para su castigo más allá de las penas que podían aplicar los tribunales de simple policía que se aplicaban en función a las circunstancias y las características de la ofensa (artículo 606 del código de delitos y penas). Este tipo de penas podían ser desde una jornada de trabajo a tres días de prisión como máximo. En cambio, los casos de ofensas sexuales, puesto que se trataban de transgresiones calificadas y clasificadas de acuerdo a las disposiciones penales del código penal, eran sometidos a la persecución por la vía criminal, lo que significa que no podían eludir a los tribunales de primera instancia o, según la gravedad, del tribunal criminal y tribunal de la audiencia. Es bajo estas circunstancias que la transacción no puede ser aceptada para resolver un conflicto mediante la simple conciliación de las partes y su intervención se restringe a las demandas de indemnización sin que por ello signifique evitar la aplicación de la pena correspondiente de acuerdo a lo estipulado en el código penal. Ante esta situación toma relevo la coexistencia de la transacción con la resolución judicial. La presencia de la transacción aunque sólo afecte al pago de una compensación por los daños sufridos por la víctima, comporta modificaciones en la interpretación y aplicación de la ley que, por consiguiente, afecta a la orientación que toma la sentencia final. 
Las transacciones en las ofensas sexuales

A través del análisis de los juicios instruidos en el Tribunal de Primera Instancia de Ceret (2.0 distrito judicial del Departamento de los Pirineos Orientales, Francia), Tribunal Criminal y Tribunal de la Audiencia del Departamento de los Pirineos Orientales, así como de la revisión de los informes trimestrales del Tribunal de la Audiencia, se ha realizado un seguimiento del uso de las transacciones en la región del Vallespir del Departamento francés de los Pirineos Orientales. A través de la observación de la práctica del derecho en distintos casos, se ha comprobado como la transacción fue un modo de resolución bastante común en los casos de violación. En estos casos la transacción actuaba como una estrategia para evitar la persecución legal que, durante el Antiguo Régimen, afectaba sobremanera a la reputación de las mujeres desestimando el daño físico y la coerción moral que en ellas recaía (Vigarello, G., 1999). A principios del s. XIX esta práctica aún persiste, coexistiendo con la posibilidad que brinda la resolución judicial. Por otra parte, esta opción mantiene a la víctima bajo el refugio del derecho sin tener que temer por el prejuicio social de la ofensa. Además, el acceso a la justicia deviene una opción disputada frente a la posibilidad de una compensación ésta ya sea en forma de pago en dinero o de ofrecimiento en bienes. Finalmente, podemos ver la actitud de los tribunales frente a esta opción a través de la sentencia final. Debido al carácter que toma la sentencia parece que las autoridades judiciales inciten a la transacción o, por lo menos, a reducir la importancia social de estos crímenes mediante la indulgencia de las penas o disminuyendo la coerción penal. Asimismo, en estos casos cuando la transacción no es aceptada por el culpable, la justicia condena con la máxima severidad. Por otra parte, la sola intención de terminar el caso por medio de la transacción ofreciendo una suma de dinero como indemnización o sugiriendo el matrimonio es suficiente para disminuir el castigo. Otros criterios son considerados con el fin de disminuir la pena, como por ejemplo la edad de las partes involucradas en el caso, el hecho que el ultraje fuera o no fuera cometido con violencia física, el estatus social del culpable y, finalmente, la existencia de relación entre ambas partes. Es decir, la introducción de la transacción, aunque sólo sea intencional, comporta haber de tener en cuenta aspectos que la ley no prevé en la evaluación de los hechos sometidos a juicio. Aspectos sociales como son la reputación que envuelve a los individuos implicados en el conflicto, el hecho que estos pertenezcan a familias influyentes en la comunidad, que tengan cierto poder adquisitivo (por ejemplo propietarios) o que ostenten cargos públicos (como oficial de salud, administrador de justicia) son algunos de los aspectos que también se toman en cuenta a la hora de pronunciar la sentencia. El temor a los escándalos 
y a la humillación que pueda recaer sobre el culpable obliga a optar por opciones que encubran y reduzcan la importancia social que adquieren estos delitos a partir de las reformas judiciales del s. XIX. Una evidencia de este éste temor es la amenaza $e$ intentos de suicidio del culpable.

\section{Conclusiones}

Para finalizar y a modo de conclusión, podemos decir que la transacción en los casos concernientes a las violencias sexuales permitió la relativización de este tipo de crímenes y, por lo tanto, la persistencia de la visión local que los delitos por ofensas sexuales merecían en la sociedad de Antiguo Régimen. Puesto que la transacción permite introducir valores y puntos de vista sociales sobre el prejuicio y su gravedad a tener en cuenta en la resolución judicial, es un instrumento a la disposición de las partes que hace posible cambiar la orientación del caso sin cuestionar la legalidad del procedimiento judicial. De esta forma la transacción permite a grupos de influencia local mantener su decisión sobre la justicia y, por lo tanto, el control sobre el derecho sobretodo si éstos se encuentran implicados en delitos tan comprometidos socialmente como los delitos por violación. Por esta misma razón las autoridades judiciales incentivan el uso de transacciones en tanto que modo de resolución de disputas establecida por negociación, y que obtiene legitimidad adaptándose a las resoluciones judiciales y a las posibilidades que proporciona la justicia establecida por adjudicación. Finalmente, decir que la transacción en tanto que relación de intercambio basada en las acciones de: a) quitar (un derecho), b) devolver (el derecho compensándolo) y c) aceptar (la compensación), se sustenta por un principio de reciprocidad al que se rinden las partes en virtud de una conveniencia común y exclusiva a sus propios intereses.

\section{Fuentes documentales inéditas}

Archivo del departamento de los Pirineos Orientales (ADPO). Perpiñan.

Procesos del Tribunal Criminal y Tribunal de la Audiencia. Serie 2 U (años VIII-1840).

Procesos del Tribunal de Primera Instancia de Ceret. Serie 3U (años VIII-1830).

Archivo Nacional de Paris (ANP). Paris.

Informes y memorias sobre el Tribunal de la Audiencia. Serie BB20 (años 1800-1850). 


\section{Fuentes documentales éditas}

Archivo del Departamento de los Pirineos Orientales (ADPO). Perpiñan.

Recueil de Jurisprudence du XIX siècle. Observations. Comentaires du point du droit écrites par Lafabrègue, advocat puis juge au Tribunal Civil de Perpignan. - décédé le 2 janvier 1867.

Traité des crimes, suivant la jurisprudence de la Cour du Conseil Souverain du Roussillon par le conseiller Noguer, Ex libris de Joseph Jaume. Manuscrito n. ${ }^{\circ} 21$.

Les codes annotés. Code civil, annoté et expliqué d'après la jurisprudence et la doctrina. Avec renvois au répertoire alphabétique de MM. Dalloz, Tome 2. Paris, au bureau de jurisprudence générale 1874 .

\section{Bibliografía}

CARBASSE, Jean-Marie (2000): Histoire du droit pénal et de la justice criminelle, Paris: PUF.

Gulliver, P. H. (1972): "Case Studies of Law in Non-Western Societies", a NADER, Laura (1972): Law in Culture and Society, Chicago: Aldine Publishing Company.

Kehlmann, $H$ (1934): De la transaction en droit romain, Paris: les éditions DomatMontechrestein.

LACANTERIE, G. Baudry (1899): Traité théorique et pratique du droit civil XXI. Des contrats aléatoires, du mandat, du cautionement de la transaction, Paris: Librairie de la Société du Recueil Générale des Lois et des Arrets.

Ploux, F (1992): "L'arrangement dans les champagnes du Haut-Quercy, 1815-1850", en Histoire de la Justice, 5, pp. 95-115.

SOULET, J.-F. (1979): "Histoire et clandestinité", Actes du colloque de la Féderation Historique du Languedoc, Toulouse, Ed. Privat, p. 239.

VERDIER, Raymond (1999): «Note pour une étude anthropologique et historique du pardon", C.I.A.J., n. ${ }^{\circ}$ 3, Le Pardon, pp. 17-22.

VIGARELLO, Georges (1999): Historia de la violación siglos XVI-XX, Valencia: Cátedra. 